\title{
TAX POLICY IN THE PRESENCE OF EMIGRATION*
}

\author{
Jagdish N. BHAGWATI \\ Columbia University, New York, NY 10027, US A
}

Koichi HAMADA

Tokyo University, Tokyo 113, Japan

Received June 1981, revised version received January 1982

\section{Introduction}

Recent policy and theoretical discussions of the effects of highly skilled migration from the underdeveloped countries, the so-called 'brain drain', have focused on a proposal [Bhagwati (1972)] to levy a (supplementary) income tax on those who migrate, the proceeds of such a tax to be transmitted to the developing country of origin or to developing countries en bloc for developmental spending. ${ }^{1}$

The welfare implications of such a tax were analyzed in an earlier paper of ours [Bhagwati and Hamada (1974)] in the context of a model of the country of emigration, characterized by sticky wages and Harris-Todaro (1971) type of unemployment. In subsequent papers, the tax has been analyzed also in the context of modified models, still incorporating the unemployment phenomena, by Rodriguez (1975) and McCulloch-Yellen $(1975){ }^{2}$ Essentially, these models analyze the impact of the income tax on emigrants' incomes as arising primarily through the reduced differential

\footnotetext{
*This paper is a significantly revised and augmented version of an earlier, unpublished paper [Bhagwati and Hamada (1976)]. Thanks are due to NSF Grant no. SCS-80-25401, to the Ford Foundation and to the German Marshall Fund for financial support of the research underlying this paper. The stimulating atmosphere at the SSRC Workshop on Public Economics at Warwick, England, 1978, also must be gratefully acknowledged by Koichi Hamada. We are also indebted to Peter Diamond, William Baumol, Assar Lindbeck, John Wilson and other participants at the New Delhi Conference in January 1981 for their helpful suggestions. The excellent comments of two referees have led to substantial improvements in this paper.

${ }^{1}$ This tax proposal has been explored from the viewpoint of its economic rationale, its revenue implications, and its legal (constitutional, tax and human rights) implications in Bhagwati and Partington (1976). The present paper can be seen as developing a yet further rationale for such a tax (in the version where the tax proceeds accrue to the country of emigration).

${ }^{2}$ For a review of these and other brain drain models in recent theoretical writings, see Bhagwati and Rodriguez (1975).
} 
between foreign (net-of-tax) and domestic salaries for the emigrant class of labor: this reduction in differential, in turn, reduces the expected and possibly the actual salaries in the home countries and thus generates consequences for education, unemployment, income and income distribution (among the educated, uneducated, employed and unemployed).

The present paper takes an altogether different, public-finance-theoretic approach to the analysis of the income tax on emigrants. We employ rather the framework of income taxation originated by Mirrlees (1971), and particularly in the form developed by Atkinson (1973). There, the choice for individuals is the length of education, which affects their productivities after graduation so that education increases the earnings of individuals while simultaneously postponing the realization of these earnings. Atkinson studies, in the context of this model, the conflict between efficiency and equity: the income tax would redistribute income but also distort the educational choice and hence reduce efficiency. ${ }^{3}$

In this paper we utilize this basic model to analyze the welfare impact of the possibility of emigration to earn incomes abroad and to assess the role of taxing migrants' incomes under alternative assumptions within the model.

Section 2 lays out the model, with the required modification to consider foreign earnings by migrants. It also outlines three policy instruments - the income tax (on domestically earned incomes), an educational subsidy, and the income tax on migrants' foreign earnings - which are appropriate to analyze in the model, for reasons spelled out herein. Section 3 considers the use of only one policy instrument, the tax on non-migrants' incomes, which we will refer to simply as the 'income tax' throughout the paper. ${ }^{4}$ Section 4 , on the other hand, considers the case where the home country can use both the income tax and an income tax on migrants' incomes, simply called hereafter an 'income tax on migrants'. ${ }^{5}$ Section 5 considers the case where all three instruments are available to the home country. Section 6 offers concluding observations, including the possible extension of our results for tax policy in relation to migrants.

\footnotetext{
${ }^{3}$ Note that lump-sum taxation to redistribute income is not being permitted; if it were, the conflict between efficiency and equity naturally would disappear! The conflict between efficiency and equity in the presence of factor mobility has also been mentioned by Cooper (1973, p. 54).

${ }^{4}$ Our model does not allow for non-migrants to earn foreign income or for migrants to earn domestic income, for simplicity. Therefore, an income tax on non-migrants income is the same as an income tax on domestically earned income.

${ }^{5}$ The United States, Philippines and (in theory) Mexico tax citizens who work abroad, regardless of length of residence or legal migration status. Therefore, the income tax on migrants', discussed in this paper is a well-established, international tax-legal policy instrument as long as migrants do not change their nationality. Under current international practices, therefore, if migrants change their nationality, the 'income tax on migrants' would become an infeasible instrument. For a lucid tax-legal discussion of these issues, see the valuable papers by Oldman and Pomp $(1975,1977,1979)$.
} 


\section{The model and policy instruments}

\subsection{The model}

Following Atkinson's model of optimal income taxation, we assume that differences exist in the innate ability of the individuals of the home country. Let $n$ be the index of innate ability and $S$ be the length of education that an individual undertakes. The innate ability in the initial population, beforc immigration possibility opens, is assumed to be distributed by the density function $p(n)$, such that

$$
\int_{n_{1}}^{\infty} p(n) \mathrm{d} n=1
$$

where $n_{1}$ indicates the lower bound of the index of innate ability. Let the domestic earning of an individual be a function of his ability and his length of education such that $f(n, S)$ indicates the resulting earnings. ${ }^{6}$ Let $f^{*}(n, S)$ be the earnings if the individual migrates and therefore has foreign earnings instead, even though we assume that he has received his education at home. These earnings are defined gross of income tax levied by the foreign country. Moreover, these earning functions are assumed to be increasing functions of $n$ and $S$, while the marginal productivity of $S$ is assumed to be nonincreasing. That is to say,

$$
\begin{aligned}
& f_{n}, f_{n}^{*}>0, \quad f_{S}, f_{S}^{*}>0, \\
& f_{S S}, f_{S S}^{*} \leqq 0
\end{aligned}
$$

with subscripts denoting the partial derivatives with respect to the subscripted variables. We further assume, for simplicity, that the length of working period after education is identical at home and abroad and designate it as $R$.

The decision whether or not to migrate is then assumed to depend on the comparison between the discounted earnings stream at home and that in the country of immigration. We assume that if the former exceeds the latter, individuals will remain at home; if the former is less than the latter, they will decide to migrate and work abroad instead. ${ }^{7}$ Further assumptions on the migration decision will be spelled out in section 3 .

${ }^{6}$ George Psacharopoulos has pointed out to us that, while it is plausible to write earnings as a function of innate ability, the econometric attempts at isolating this relationship have not been particularly successful so far.

${ }^{7}$ We could have assumed instead that only a fraction of those who could earn more abroad would choose to migrate, with this fraction an increasing function of the difference between income earned by migrating and domestic income. However, our assumption simplifies the analysis while sacrificing nothing that is critical. 


\subsection{The policy instruments}

With this basic framework set up, we now list the three policy instruments that we will consider in the paper.

(1) Linear income tax. Following Atkinson (1973), a linear income tax implies that the after-tax (non-migrants') income will be written in the form $[\alpha+\beta f]$, where $\alpha>0,1>\beta \geqq 0,(1-\beta)$ is the marginal rate of taxation and $\alpha$ constitutes the uniform lump-sum payment to each individual.

(2) Subsidy to education. Following Hamada (1974), who demonstrated that the use of an appropriate educational subsidy could virtually resolve the Atkinson conflict between equity and efficiency, an educational subsidy will be considered as implying that the subsidy $(G)$ is given directly to individuals enrolled in the educational system.

(3) Linear income tax on migrants. Following Bhagwati, we will consider a linear income tax on migrants so that their after-home-country-tax income can be written in the form $\left[\alpha^{*}+\beta^{*} f^{*}\right]$, with the asterisk indicating migrants. If we assume that the country of immigration levies its own income tax on the migrants' income such that $y^{*}=\gamma+\delta f^{*}$, where $y^{*}$ is then the net-ofimmigration-country-tax income of the migrant, and that the home country's income tax on migrants is levied on $y^{*}$ so as to leave the migrant finally with net income equal to $\left[t+\tau y^{*}\right\rceil$, then we must have $\alpha^{*}+\beta f^{*}=t+\tau\left(\gamma+\delta f^{*}\right)$ so that we obtain the following relationship between the tax parameters: ${ }^{8}$

$$
\alpha^{*}=t+\tau \gamma ; \quad \beta^{*}=\tau \delta .
$$

(4) The welfare criteria. Next, we note that three alternative welfare criteria might be deployed to analyze the outcomes under these alternative policy combinations. (a) We will generally deploy the criterion of the welfare impact of the migration on those left behind (TLBs), examining in turn their average income or utility and alternatively the minimum income among them à la Rawls (1971). (b) Alternatively, we could have examined the welfare impact on TLBs plus the migrants: ${ }^{9}$ as discussed briefly in the concluding section. ${ }^{10}$ (c) Finally, we could have taken a global or 'internationalist' criterion embracing the non-migrant nationals of the country of immigration as well in a two-country framework.

\footnotetext{
${ }^{8}$ Note that the linearity of the income tax on migrants is assumed here, parallel to Atkinson's income tax, but is not a necessary feature of the proposal in Bhagwati (1972).

${ }^{9}$ This criterion would seem more consistent with the view that many migrants do not change their nationalities today and hence are, from a legal and sociological viewpoint, mombers of the home country. Cr. Bhagwati (1979).

${ }^{10}$ Wilson considers, in his illuminating paper (1978) based on the leisure-work choice model of Mirrlees (1971), the effect of migration on the optimal linear tax rate, assuming that the only policy instrument is the income tax (on domestic residents).
} 


\section{Income tax in the presence of migration}

We now consider the case, applicable to countries which neither subsidize education nor exercise their income tax jurisdiction over citizens working abroad, where the home country has only an income tax (on domestic incomes) at its command. Precisely, we will analyze the welfare impact on TLBs when, in the presence of the possibility of migration to work abroad, the income tax is levied at an optimal rate. ${ }^{11}$ Our reference point will be the standard Atkinson solution where the possibility of migration is not allowed, so that we will then be able to deduce what the introduction of the possibility of migration implies for the welfare of the TLBs and the associated optimal parameters/rates of income taxation.

\subsection{Two fundamental individual decisions}

We begin by first indicating how the possibility of migration to earn foreign income will influence the two fundamental choices facing an individual in this modified Atkinson economy: (1) the choice of the length of education; and (2) the decision to migrate or work at home. Note immediately, however, that in the Atkinson model without migration, efficiency is sacrificed for equity, the loss of efficiency taking the form of a reduced length of education since individuals are taxed on their (educationaugmented) earnings. In our modified version with migration, on the other hand, the sacrifice of efficiency will occur on two dimensions: a distorted length of education by migrants and non-migrants, and overmigration since migrants escape (whereas non-migrants must pay) the income tax because the home country fails to exercise its tax jurisdiction over citizens working abroad.

\subsubsection{Choice of length of education}

Assuming throughout that education is always undertaken at home, we can see that an individual will maximize his lifetime income from domestic earnings, $I_{\mathrm{d}}$, with respect to $S$ (the length of education). Now,

$$
\begin{aligned}
I_{\mathrm{d}} & =\int_{S}^{S+R}(\alpha+\beta f(n, S)) \mathrm{e}^{-i t} \mathrm{~d} t \\
& =A(\alpha+\beta f) \mathrm{e}^{-i S},
\end{aligned}
$$

where $i$ is the rate of discount, $R$ is the length of working period, and $A \equiv$

\footnotetext{
"The optimality will reflect the precise choice of the objective function, of course.
} 
$\left(1-\mathrm{e}^{-i R}\right) / i$. Since we assume that $R$ is constant, ${ }^{12} A$ can also be regarded as a constant. Maximizing $I_{\mathrm{d}}$ with respect to $S$, we then obtain the first-order condition for a privately optimal decision:

$$
A\left\{-i(\alpha+\beta f)+\beta f_{S}\right\}=0 .
$$

The second-order condition is satisfied because of the assumption that $f_{S S} \leqq 0$.

Similarly, if the individual concentrates on foreign earnings as a migrant, he will maximize

$$
\begin{aligned}
I_{\mathrm{f}} & =\int_{S}^{S+R}\left(\alpha^{*}+\beta^{*} f^{*}(n, S)\right) \mathrm{e}^{-i t} \mathrm{~d} t-C \mathrm{e}^{-i S} \\
& =A\left(\alpha^{*}+\beta^{*} f^{*}\right) \mathrm{e}^{i S}-C \mathrm{e}^{-i S},
\end{aligned}
$$

where $C$ is the lump-sum cost of migration (e.g. transportation, etc.) that is incurred at the time of departure, $f^{*}(n, S)$ is the foreign income to be earned before tax by an individual with index $n$, and $\left(\alpha^{*}+\beta^{*} f^{*}\right)$ is the foreign income of the migrant net of all income taxation. Recall from our earlier discussion of policy instruments that when the home country does not tax citizens abroad, $\alpha^{*}$ and $\beta^{*}$ will equal the parameters of the income tax schedule of the foreign country, i.e. $\alpha^{*}=\gamma$ and $\beta^{*}=\delta$.

The corresponding first-order condition for the migrants' privately optimal decision then is yielded by maximizing $I_{\mathrm{f}}$ with respect to $S$, and is

$$
A\left\{-i\left(\alpha^{*}+\beta^{*} f^{*}\right)+\beta^{*} f_{S}^{*}\right\}+i C=0 .
$$

\subsubsection{Decision to migrate and work abroad}

Next, consider the problem of the choice between staying at home and working abroad. As stated above, potential migrants are assumed to decide whether or not to migrate by comparing the discounted value of income streams to be obtained from home and abroad. They decide to migrate therefore if the following expression is positive, and not to migrate if it is non-positive:

$$
\Gamma(n)=\left\{A\left(\alpha^{*}+\beta^{*} f^{*}\left(n, S^{*}\right)\right) \mathrm{e}^{-i S^{*}}-C e^{-i S^{*}}\right\}-A(\alpha+\beta f(n, S)) \mathrm{e}^{-i S} .
$$

\footnotetext{
${ }^{12}$ Alternatively, we may assume that the total length $(S+R)$ of life, instead of $R$, is constant. However, this does not change our main results, as indicated by Hamada (1974). In fact, it even simplifies some expressions. For example, the optimal subsidy formula becomes $G=\alpha$ instead of $G=A i \alpha$.
} 
Here $S$ and $S^{*}$ indicate, respectively, the length of education given the opportunity to work at home or abroad.

To facilitate our analysis, we additionally assume now that, corresponding to the parameters of the income tax schedules of the home country and the foreign country, there is a unique value $n^{*}$ of ability above which everyone will migrate. ${ }^{13}$ Hence:

$$
\begin{aligned}
& \Gamma(n)>0, \quad \text { if } n>n^{*}, \\
& \Gamma(n) \leqq 0, \quad \text { if } n \leqq n^{*} .
\end{aligned}
$$

Evidently, the value of $n^{*}$ depends on the tax parameters, $\alpha$ and $\beta$, through their effect on realized discounted incomes. Moreover, since $\beta$ 's effect on this income equals $\alpha$ 's effect multiplied by $f(n, \hat{S})$, we can show that: ${ }^{14}$

$$
\frac{\partial n^{*}}{\partial \alpha}>0 ; \quad \frac{\partial n^{*}}{\partial \beta}=f\left(n^{*}, \hat{S}\right) \frac{\partial n^{*}}{\partial \alpha}>0 .
$$

Next, reflecting the reality that (thanks to the nature of immigration restrictions which are biased in favor of professional, skilled immigrants) migration is feasible often for the skilled alone, we will assume that this

\footnotetext{
${ }^{13}$ The analysis of the more general possibility where migration is feasible over the entire interval of ability endowment is considerably more complex. Cf. Wilson (1978).

${ }^{14}$ With given values $\alpha^{*}$ and $\beta^{*}, n^{*}$ is determined by

$$
I_{\mathrm{d}}\left(\alpha, \beta, n^{*}\right)-I_{\mathrm{f}}\left(\alpha^{*}, \beta^{*}, n^{*}\right)=0 .
$$
}

Therefore

$$
\frac{\partial I_{\mathrm{d}}}{\partial \alpha} \cdot \mathrm{d} \alpha+\frac{\partial I_{\mathrm{d}}}{\partial \beta} \cdot \mathrm{d} \beta+\frac{\partial I_{\mathrm{d}}}{\partial n^{*}} \cdot \mathrm{d} n^{*}-\frac{\partial I_{\mathrm{f}}}{\partial n^{*}} \cdot \mathrm{d} n^{*}=0
$$

Thus

$$
\begin{aligned}
& \left.\frac{\partial n^{*}}{\partial \alpha}\right|_{\beta=\text { consı. }}=\frac{\partial I_{\mathrm{d}}}{\partial \alpha} /\left\{\frac{\partial I_{\mathrm{f}}}{\partial n^{*}}-\frac{\partial I_{\mathrm{d}}}{\partial n^{*}}\right\} \\
& \left.\frac{\partial n^{*}}{\partial \beta}\right|_{\gamma=\text { nnst }}=\frac{\partial I_{\mathrm{d}}}{\partial \beta} /\left\{\frac{\partial I_{\mathrm{f}}}{\partial n^{*}}-\frac{\partial I_{\mathrm{d}}}{\partial n^{*}}\right\} .
\end{aligned}
$$

Now, from the expressions of $I_{\mathrm{d}}$ and $I_{\mathrm{f}}$, we have:

$$
\frac{\partial I_{\mathrm{d}}}{\partial \beta} / \frac{\partial I_{\mathrm{d}}}{\partial \alpha}=f(n, S) .
$$

Moreover, since the assumption underlying relation (4) presupposes that $\left[\left(2 I_{\mathrm{f}} / \mathrm{\partial} n\right)-\left(\partial I_{\mathrm{d}} / \mathrm{C} n\right)\right]$ is positive in the neighborhood of $n^{*}$, it follows that both $\partial n^{*} / \partial \alpha$ and $\partial n^{*} / \partial \beta$ are positive. 
critical value $n^{*}$ is larger than the mean value $\bar{n}$ of the ability index, i.e.

$$
n^{*}>\bar{n}
$$

Finally, the reader may find it illuminating to consider the critical value $n^{*}$ in fig. 1 , where $I_{\mathrm{d}}$ and $I_{\mathrm{f}}$ are drawn as functions of the ability index $n$ and the given tax parameters. Our assumption underlying (4) implies that the $I_{1}$ curve intersects the $I_{\mathrm{d}}$ curve from below only once, with the value of $n$ at the intersection being $n^{*}$. $I_{\mathrm{d}}$ shifts upward with an increase in either $x$ or $\beta$. However, the increase in the latter case is proportionally $f(n, S)$ times greater than in the former case. It follows that the value of $n^{*}$ will increase with either $\alpha$ or $\beta$, as in (5).

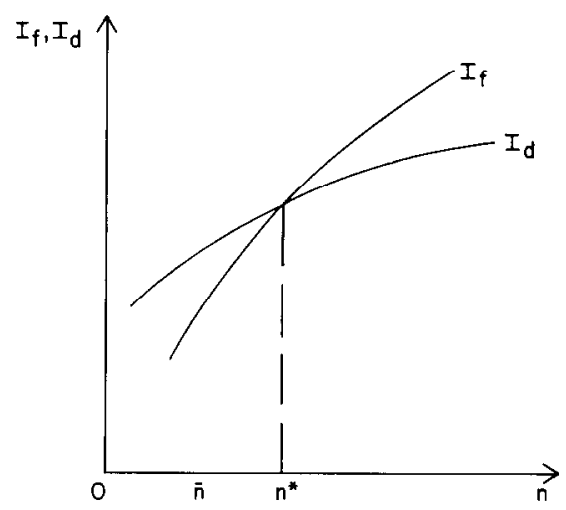

Fig. I

\subsection{Defining TLBS}

Next, before we undertake our analysis of the nature of the optimal income tax schedule in the presence of migration, we must carefully consider the implication of the welfare criterion we plan to adopt, i.e. the impact on TLBs. For, one final complexity needs to be cleared up in discussing the TLBs in our modified Alkinson economy. The TLBs turn out, in general, to be a variable number of individuals because the critical value $n^{*}$ that serves to divide the population in the home country into migrants and nonmigrants is a function of the tax parameters, $\alpha$ and $\beta$. Thus, if we were to compare (say) the average welfare of TLBs under one set of $(\alpha, \beta)$ with the average welfare of TLBs under another set of $(\alpha, \beta)$, we would in fact be comparing different subsets of original population. ${ }^{15}$ To avoid this difficulty, we resort to the following stratagem. We take a value $N$ such that $N \leqq n^{*}$ for

\footnotetext{
'And we would have an ill-defined problem! Cf. Hamada (1975).
} 
all $n^{*}$ 's associated with the range of tax parameters, ${ }^{16} \alpha$ and $\beta$, that emerge in our analysis. We then redefine TLBs to include only those whose ability index lies in the interval $\left[n_{1}, N\right]$. This procedure clearly avoids the ambiguity concerning the size of the TLB population by making it invariant to changes in $n^{*}$.

\subsection{The formal optimization problem}

We are now in a position to analyze the optimal choice of the tax parameters, $\alpha$ and $\beta$, in this modified, 'open' Atkinson economy. Consider first the utilitarian criterion for judging welfare impact on TLBs. We then have the formal problem of maximizing ${ }^{17}$

$$
\int_{n_{1}}^{N} U\left(I_{\mathrm{d}}(n, \alpha, \beta)\right) p(n) \mathrm{d} n
$$

subject to the budget constraint

$$
\alpha \int_{n_{1}}^{n^{*}} p(n) \mathrm{d} n=(1-\beta) \int_{n_{1}}^{n^{*}} f(n, S) p(n) \mathrm{d} n .
$$

The general solution to this problem being difficult to secure, we assume the particular forms of earning function, distribution-of-ability function and the utility function that were assumed by Atkinson (1973) in the original analysis without migration. Thus, our earning function will be

$$
f(n, S)=n S
$$

and we will use the Pareto distribution whose density function is written as:

$$
\begin{aligned}
p(n) & =\mu n^{-\mu-1}, & & \text { for } n \geqq 1 \\
& =0, & & \text { for } n<1,
\end{aligned}
$$

where $\mu$ is parametrically assumed to exceed 2 and $n_{1}$ is assumed to equal unity. ${ }^{18}$ It follows also from eq. (6) that

$$
n^{*}>\mu /(\mu-1)=\bar{n}
$$

\footnotetext{
${ }^{16}$ This requirement is in fact stronger than needed. If we solve the problem following the procedure discussed below for an arbitrary $N$, and if the resulting optimal tax parameters $x$ and $\beta$ do not give rise to $n^{*}$ smaller than $N$, then our our analysis is completely legitimate.

${ }^{17}$ Recall that $I_{\mathrm{d}}(n, \alpha, \beta)$ is the discounted value of income stream for individuals with ability $n$ and with disposable income $\{\alpha+\beta f(n, S)\}$.

${ }^{18}$ So long as the Pareto distribution is assumed, the restriction on $n_{1}$ does not change the value of the optimal tax rate in a closed economy. We owe this observation to Tony Atkinson. [Cf. Atkinson (1973)].
} 


\subsection{The optimal choice of tax parameters}

Our analysis then proceeds by first discussing the implications of individual optimizing behaviour in this model, second deriving the feasibility locus between the tax parameters that this behavior implics in the presence of the restriction that the government's budget be balanced, and finally utilizing this tax feasibility locus to derive the optimal choice of the tax parameters, given the welfare criterion adopted.

\subsubsection{Individual optimization}

The individual optimization implies that the non-migrant will choose the length of education so as to maximize

$$
I_{\mathrm{d}}=A(\alpha+\beta n S) \mathrm{e}^{-i S}
$$

which, under the assumption that everybody spends some time in educating himself, will result in:

$$
\begin{aligned}
& \hat{S}=\frac{1}{i}-\frac{x}{\beta n}, \\
& n S=\frac{n}{i}-\frac{x}{\beta},
\end{aligned}
$$

and

$$
I_{\mathrm{d}}=A \frac{\beta n}{i} \exp \left(\frac{\alpha i}{\beta n}-1\right)=A \frac{\beta n}{i e} \exp \left(\frac{n_{0}}{n}\right)
$$

where $n_{0}=\alpha i / \beta$.

\subsubsection{Tax feasibility loci}

Next, given this individual-optimizing behavior, we can derive the tax feasibility locus, reflecting additionally the government's budget constraint. Following Atkinson, we derive this for $\beta$ and $n_{0}=i \alpha / \beta$ (rather than $\alpha$ and $\beta$ ), where $n_{0}$ corresponds to the value of the ability index where an individual stops educating himself. In a closed economy, $n_{0}$ is smaller than unity if $\mu>2$. This justifies the above assumption that everybody spends some time in educating himself. ${ }^{19}$ Thus, we shall follow this assumption throughout the

\footnotetext{
${ }^{19} \mathrm{See}$ Atkinson (1973, p. 100. footnote 2). Since the optimal $n_{0}$ in an open model is smaller then the optimal $n_{0}$ in the corresponding closed model [cf. fig. 2, and proposition 3(2)], we can justify this assumption in an open model as well.
} 
paper. Thus, we note that the budget constraint (8) can be expressed as:

$$
\alpha \int_{1}^{n^{*}} p(n) \mathrm{d} n=(1-\beta) \int_{1}^{n^{*}}\left(\frac{n}{i}-\frac{\alpha}{\beta}\right) p(n) \mathrm{d} n,
$$

where $n^{*}$ itself is a function of $\alpha$ and $\beta$. Moreover, by substituting the Pareto distribution, we get:

$$
\alpha\left(1-n^{*-\mu}\right)=(1-\beta)\left\{\frac{\bar{n}}{i}\left(1-n^{*-\mu+1}\right)-\frac{\alpha}{\beta}\left(1-n^{*-\mu}\right)\right\} .
$$

Following Atkinson's procedures, we can then deduce the following, critical relationship:

$$
\beta=1-\frac{n_{0}}{\bar{n}} \cdot \frac{1-n^{*-\mu}}{1-n^{*-\mu+1}}=1-\frac{n_{0}}{\bar{n}} h\left(n^{*}\right),
$$

where $h\left(n^{*}\right) \equiv\left(1-n^{*-\mu}\right) /\left(1-n^{*-\mu+1}\right)$.

Now, it is readily seen that if we were to 'close' this economy and eliminate migration, $n^{*} \rightarrow \infty$ and $h\left(n^{*}\right)$ reduces to unity. The tax feasibility loci for the "closed' (i.e. without-migration) economy and for the 'open' (i.e. with-migration) economy, depicting the relationship between $\beta$ and $n_{0}$ from (14), are drawn in fig. 2 with a straight line $A C$ for the former case and with a curve $A B$ for the latter.

Before proceeding to the last step of choosing the optimal tax parameters from this feasible set, however, we must investigate the properties of these loci. First, we must note that the closed-economy locus will be straight line.

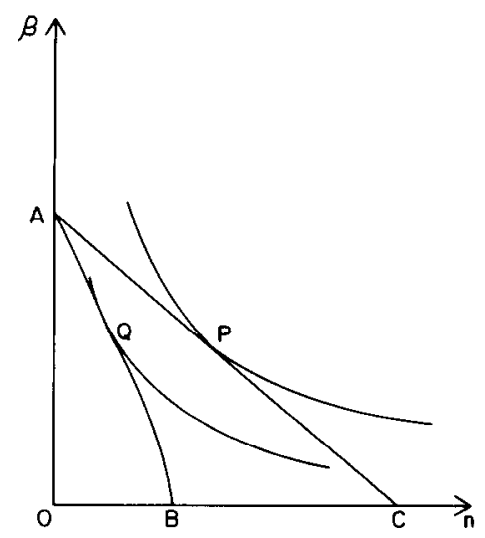

Fig. 2 
Moreover, since (as shown in the appendix, remark 1) $h\left(n^{*}\right)>1$ for the relevant values of $n^{*}>2$ and $\mu>2$, the tax feasibility locus for the open economy must lie below that for the closed economy (except when $n_{0}=0$ ).

Second, the slope of the tangent line for the tax feasibility locus for the open economy can be shown everywhere to be steeper than the (unique) slope of the focus for the closed economy. That is to say (as per the appendix. remark 3), we can show that

$$
-\frac{\mathrm{d} \beta}{\mathrm{d} n_{0}}>\frac{1}{\bar{n}}
$$

\subsubsection{The logarithmic utility function}

Now we can turn to the optimal choice of the tax parameters, given these tax feasibility loci. With Atkinson, we will begin with the utilitarian welfare criterion, i.c. we will maximize the average utility of TLBs. ${ }^{20}$ Following $\Lambda$ tkinson again, we will initially assume a specific utility function, i.e. the logarithmic utility function. In this case the utilitarian objective is written as:

$$
\begin{aligned}
& \int_{1}^{N} \log \left\{\frac{\beta n}{i e} \exp \left(\frac{n_{0}}{n}\right)\right\} p(n) \mathrm{d} n \\
& \quad=\text { const. }+\log \beta \int_{1}^{N} p(n) \mathrm{d} n+n_{0} \int_{1}^{N} n^{1} p(n) \mathrm{d} n .
\end{aligned}
$$

The social indifference map for the population with ability between 1 and $N$ can then be obtained by equating the above expression to a constant, and the indifference curves can then be drawn convex, as in fig. 2. Moreover, the slopes of the tangent lines to the indifference curves are identical for a given value of $\beta$ or, in other words, the tangent lines are parallel along any hozizontal line, because the slope

$$
-\frac{\mathrm{d} \beta}{\mathrm{d} n_{0}}=\beta \frac{\int_{1}^{N} n^{-1} p(n) \mathrm{d} n}{\int_{1}^{N} p(n) \mathrm{d} n}
$$

does not depend on the value of $n_{0}$.

We then arrive immediately at two important conclusions, noticing that the optimal tax parameters chosen by the TLBs will reflect the tangency of a

\footnotetext{
${ }^{20}$ In Atkinson's analysis the economy is closed of course. Our analysis of the open economy. on the other hand, applies the utilitarian criterion to TLBs alone.
} 
social indifference curve with the tax feasibility locus, i.e. eq. (15) with (17). First, the welfare level attained by the TLBs is strictly inferior to that in a closed economy, because the feasibility locus of an open economy is inside that for a closed economy. ${ }^{21}$ Second, we see that the home country, pursuing the utilitarian objective on behalf of TLBs, will choose a lower marginal tax rate $(1-\beta)$ if the economy is open rather than closed: the emigration possibility, in this sense, forces a less egalitarian policy on the home country. To see this, consider fig. 2 again. If the economy is closed, point $P$ will be chosen; if it is open, point $Q$ will be chosen. Because the tangency slope of the indifference curves along the horizontal line through $P$ is constant, and because the tangency slope of the opportunity curve for an open economy is steeper than that of the dotted line as indicated by (15), the vertical coordinate of $Q$ must be larger than that of $P$. Since the marginal rate of taxation equals $(1-\beta)$, this amounts to choosing a lower marginal tax rate if the economy is open.

\subsubsection{The iso-elastic utility function}

We turn next to the more general case of an iso-elastic utility function:

$$
U=\frac{I_{\mathbf{d}}^{1} \rho}{1-\rho}, \quad \rho \geqq 0, \quad \rho \neq 1,
$$

where $\rho$ indicates the degree of inequality-aversion of society and, as is well known, this utility function converges to a logarithmic function when $\rho$ approaches unity. The welfare of TLBs can then be expressed as:

$$
W=\frac{A^{\prime}}{1-\rho} \int_{1}^{N} \beta^{1-\rho_{n}} n^{1-\rho} \exp \left(\frac{(1-\rho) n_{0}}{n}\right) p(n) \mathrm{d} n,
$$

where $A^{\prime}=$ const. The marginal rate of substitution between $\beta$ and $n_{0}$ can then be written as:

$$
\begin{aligned}
& -\frac{\mathrm{d} \beta}{\mathrm{d} n_{0}} \\
& =\beta \int_{1}^{N} n^{-\rho} \exp \left(\frac{(1-\rho) n_{0}}{n}\right) p(n) \mathrm{d} n /\left[\int_{1}^{N} n^{1-\rho} \exp \left(\frac{(1-\rho) n_{0}}{n}\right) p(n) \mathrm{d} n\right] .
\end{aligned}
$$

Along a horizontal line, such that $\beta$ is constant, this absolute slope of the indifference curve can be shown to be an increasing function of $n_{0}$ if $\rho<1$,

${ }^{2}$ This was shown also in Hamada (1975). 
and a decreasing function of $n_{0}$ if $\rho>1$ (cf. the appendix, remark 4). This has immediate consequences for the optimal choice of the tax parameters in our open economy vis-à-vis the closed economy.

Thus, if $\rho<1$, exactly the same argument as for the case of the logarithmic utility function applies and the open economy will be characterized by the choice of a lower marginal tax rate. (Note that when $\rho=0$, we have the linear utilitarian criterion and we are maximizing average income.)

On the other hand, if $\rho>1$, i.e. the inequality-aversion exceeds that in the logarithmic case, the tangency slopes to the indifference curves become steeper as one moves horizontally to the left of $P$. Ilence, we cannot assert now that the marginal rate of income taxation is necessarily less for the open economy. ${ }^{22}$

This paradoxical possibility when $\rho>1$, however, can be shown to be ruled out in the extreme, Rawlsian case where, as is well known, we are dealing with the limiting case of the utilitarian welfare criterion when $\rho \rightarrow \infty$. In this extreme case of inequality-aversion, where we are maximizing the discounted income of the individual with the lowest ability, we can write this discounted income, since $n_{1}=1$, as:

$$
I_{\mathrm{d}}=A \frac{\beta}{i e} \mathrm{e}^{n_{0}},
$$

so that we have the indifference curve:

$$
\beta \mathrm{e}^{n_{0}}=\text { const., }
$$

with a marginal rate of substitution, $-\mathrm{d} \beta / \mathrm{d} n_{0}=\beta$, which is independent of $n_{0}$. Hence, the argument can proceed exactly as with the logarithmic utilitarian case (i.e. $\rho=1$ ), and therefore the open economy would be characterized by a lower marginal tax rate.

\subsection{Three major propositions}

We can therefore summarize our results thus:

Proposition 1. The welfare level of the TLBS is definitely inferior in an open, vis-à-vis the closed, economy.

Proposition 2. If the individual utility function is iso-elastic with $\rho \leqq 1-$ the logarithmic function, with $\rho=1$, and the linear function, with $\rho=0$, being two

\footnotetext{
${ }^{22}$ The deviation from $1 / n$ of the slope of the tax feasibility locus is independent of the deviation of the langency slope of indifference curves from the slope at $P$. Therefore, one may get the paradoxical situation in the text if $h\left(n^{*}\right)$ is very close to unity, i.e. the possibility of emigration is very small.
} 
special cases - then the criterion of maximizing the welfare of TLBS will lead to choice of a reduced marginal tax rate for an open economy.

Proposition 3. (1) If, however, $\rho>1$, one cannot preclude the possibility that the open economy is characterized by an increased marginal tax rate. (2) For the extreme Rawlsian case, where $\rho \rightarrow \infty$, the open economy, however, will be characterized by a lower marginal tax rate.

\subsection{Efficiency implications}

Our analysis has focused thus far on the effect on the choice of the tax parameters, and the associated welfare impact on TLBs, when the economy is open. In doing this we demonstrated the deterioration in the tax feasibility locus that the migration possibility entails. Now, however, we shift our focus to a related, but distinct, question: How precisely does efficiency get compromised in our open Alkinson economy? ${ }^{23}$

We must distinguish between domestic (i.e. home-country) and global efficiency. By the former, we will mean the equalization of the relevant marginal rates of substitution (MRS) within the home country. By the latter, we will mean the equalization of the MRS within the home country and between the home and foreign countries.

But we will define global efficiency in a restricted fashion: the foreign country will be assumed to be behaving optimally vis-à-vis its own population, setting its own tax parameters correspondingly. Global efficiency will then be defined purely in the sense that the home country migrants' decision to migrate must reflect the comparison of their gross, unadjusted productivities/returns.

Moreover, we must note that domestic efficiency is not tantamount to maximization of domestic income since the latter would also reflect the distribution of world income among the two countries.

\subsubsection{Domestic efficiency}

Now, domestic efficiency requires the individual non-migrant to choose the socially optimal amount of education. The corresponding first-order condition, necessary for a maximum, is yielded by maximizing: ${ }^{24}$

$$
\int_{S}^{S+R} f(n, S) \mathrm{e}^{-i t} \mathrm{~d} t=A f \mathrm{e}^{-i S}
$$

\footnotetext{
${ }^{23}$ This question is pertinent to our analysis in section 5 .

${ }^{24}$ In order that the individual productivity maximization over time coincides with the socially optimal choice, we need to use the correct discount rate. As discussed in Hamada (1972), the correct discount rate should be the biological rate of interest, i.e. the growth rate of the population (plus the posiitive rate of labor-augmenting technical progress).
} 
which yields:

$$
A\left\{-i f+f_{S}\right\}=0 \text {. }
$$

This condition is evidently not met in our Atkinson cconomy where, it will be recalled, individuals optimize so as to satisfy

$$
\left.A\}-i(\alpha+\beta f)+\beta f_{S}\right\}=0
$$

The equality of (22) and (2) would require that $\alpha=0$ and $\beta=1$, i.e. the absence of income taxation!

If we consider next the migrants" income as part of domestic income, there is a similar failure of equality between the migrants' choice of the individually optimal length of education and the socially optimal choice thereof. The former will imply

$$
A\left\{-i\left(\alpha^{*}+\beta^{*} f^{*}\right)+\beta^{*} f_{S}^{*}\right\}+i C=0
$$

whereas the latter will require

$$
A\left\{-i f^{*}+f_{S}^{*}\right\}+i C=0
$$

and (22a) and (2a) will not be equal unless $\alpha^{*}=0$ and $\beta^{*}=1$

\subsubsection{Global efficiency}

In addition to satisfying the preceding two first-order conditions, (22) and (22a), for a globally optimal choice (in the restricted sense as defined above) of the educational length, global efficiency further requires that the decision to migrate depend on whether the following expression is positive or not:

$$
\begin{aligned}
\hat{\Gamma}(n) & =\int_{S^{*}}^{S^{*}+R} f^{*}\left(n, \hat{S}^{*}\right) \mathrm{e}^{i t} \mathrm{~d} t-C \mathrm{e}^{i \bar{S}^{*}}-\int_{\hat{S}}^{\hat{S}+R} f(n, \hat{S}) \mathrm{e}^{i t} \mathrm{~d} t \\
& =\left\{A f^{*}\left(n, \hat{S}^{*}\right)-C\left(\mathrm{e}^{-i S^{*}}-A f(n, S) \mathrm{e}{ }^{i \hat{S}},\right.\right.
\end{aligned}
$$

where $\hat{S}$ and $\hat{S}^{*}$ are the values of $S$ and $S^{*}$ satisfying (22) and (22a). However, the actual decision to migrate is made depending instead on whether (3) is positive or non-positive. Unless, therefore, coincidentally $\beta=\beta^{*}=1$ and $\alpha=\alpha^{*}$, the two conditions will be different. With only domestic income tax available as a policy instrument, the home country cannot affect the values of $\alpha^{*}$ and $\beta^{*}$, which are solely determined by the foreign government. Thus, this third and final requirement for (restricted) global efficiency will not be met cither. 


\section{Income tax and income tax on migrants in the presence of migration}

Consider now a modification to the Atkinson, open economy. In addition to the (domestic) income tax, let us now utilize also an income tax on migrants. The effect of this is essentially to close the economy from the viewpoint of the budget constraint. This, however, will not restore, in general, the tax feasibility locus of the closed economy without migration even if the income tax is uniformly applied to non-migrants' domestic incomes and migrants' net-of-foreign-tax foreign incomes.

For, as long as (some) migrants' net-of-foreign-tax incomes exceed what they could earn domestically, corresponding to any educational level, this is tantamount to keeping the economy closed to migration but increasing the productivity of these 'migrants'. Hence, evidently, the tax feasibility locus of the open economy with such utilization of the added policy instrument constituted by the income tax on migrants will dominate that for the closed cconomy confined only to the use of the (domestic) income tax, the latter in turn dominating of course the tax feasibility locus for the open economy confined to the (domestic) income tax.

In fig. 3 this is illustrated by the numbered tax feasibility loci in terms of $\alpha$ and $\beta$ referring to the open economies and the locus $C$ referring to the closed economy. Locus $I I$ is the locus for the open economy with income tax on migrants' net-of-foreign-tax incomes at the same rates as the tax on nonmigrants' domestic incomes (assuming that these incomes exceed what the migrants would have earned (gross) domestically), i.e. when

$$
t=\alpha \quad \text { and } \quad \tau=\beta
$$

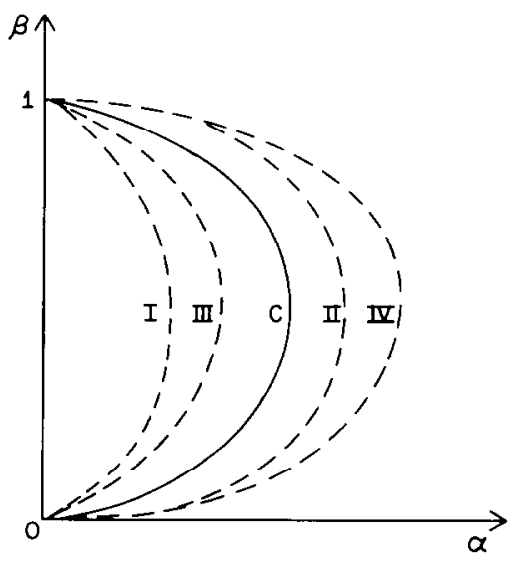

Fig. 3 
in terms of eq. (5). Locus $I$, on the other hand, is the tax feasibility locus when the open economy cannot use the income tax on migrants. In fig. 3 , locus $I I$ locus $C \supset$ locus $I$.

If the home country were to use 'prohibitive' tax rates on migrants, $t$ and $\tau$, so that it pays migrants to stay home, we revert of course to the closed economy locus $C$. On the other hand, the home country could set these tax rates, $t$ and $\tau$, 'monopolistically' so as to extract the entire rent, if any, from the migrants' working abroad rather than at home, in which case the corresponding tax feasibility locus $I V$ will be the 'best' one; but it is likely to run afoul of explicit human-rights conventions!

On the other hand, choosing the tax parameters $t$ and $\tau$ at values that substantially reduce the migrants' tax liability to the home country will result in a shrinking-in of the tax feasibility locus. In the limiting case of zero income tax on migrants, it will revert to locus $I$, but will otherwise dominate it. However, it may be dominated in turn by the closed economy locus, as when it is locus $I$ in fig. 3, where locus $I \subset$ locus $I I I \subset$ locus $C$.

While all this is perfectly clear, it is not possible, without added restrictions, to say anything more than that the availability of the income tax on migrants generally permits the tax feasibility locus to be improved over that in the open economy without this added policy instrument. Hence, whether one maximizes TLB welfare more generally or takes the extremo Rawlsian case, it would be possible to improve welfare with the use of the income tax on migrants. ${ }^{25}$

At the same time, it is important to note that the income tax on migrants can be utilized so as to correct the choice on migration so as to fulfill the global-efficiency requirement that the migrants choose to migrate when their gross, unadjusted incomes abroad exceed the gross, unadjusted incomes at home. However, it cannot obviously be used to correct the inefficiency of the choice regarding the length of education (which requires the use of the educational subsidy, as already discussed in the preceding section).

\section{All three policy instruments: Global efficiency and TLB welfare maximization}

Now, we know from section 4 that an income tax on migrants can be used to correct the choice on migration but cannot correct for the inefficiency in the choice of educational length as required for domestic efficiency. At the same time, it is evident that the use of an educational subsidy can assist in achieving domestic efficiency but cannot correct for the socially inefficient

\footnotetext{
${ }^{25}$ We have therefore not elevated this simple, but important, conclusion into a proposition in the text. Note also that we could say something more if we were to attempt a solution to the very difficult analytical problem of choosing $x, \beta, t$ and $\tau$ so as to secure the best tax feasibility locus in the "monopolistic" case discussed in the text.
} 
(from the global viewpoint in the restricted sense discussed above) choice on migration. It should be evident, therefore, that the use of both the educational subsidy and the income tax on migrants ought to enable us to achieve domestic and global efficiency.

An interesting problem for us to analyze, therefore, is the characterization of the optimal levels of these policy instruments. Moreover, it would be important to ask whether, if the educational subsidy and the income tax on migrants were set in this way so as to achieve domestic and global efficiency, the tax feasibility locus for this open Atkinson economy would lie outside the tax feasibility locus for the open Atkinson economy which cannot use these policy instruments at all. In fact, it will. Therefore, we can argue that the use of the income tax, the income tax on migrants and the educational subsidy at appropriate values can both achicve domestic and global efficiency and improve the welfare of TLBs, vis-à-vis an economy that uses only the income tax and experiences migration. Indeed, we can go further and show that this global efficiency solution will also be characterized by virtual, full equity and will, in fact, be the first-best solution for TLB welfare.

\subsection{Achieving global efficiency}

Thus, consider first the achievement of (restricted) global efficiency by a suitable use of the three policy instruments, by examining the three choices in our model: the choice of the educational lengths for non-migrants and migrants respectively, and the decision to migrate.

\subsubsection{Choice of the lengths of education}

As for the educational choice of the non-migrant, it is easy to see that the first-order condition for a private maximum will be given by

$$
A\left\{-i(\alpha+\beta f)+\beta f_{s}\right\}+G=0,
$$

as shown in Hamada (1974) for a closed economy, and where $G$ is the educational subsidy. On the other hand, we get from (22) the first-order condition for a social maximum as: $A\left\{-i f+f_{S}\right\}=0$. Hence, equality between (22) and (24) implies an educational subsidy such that

$$
G=A i \alpha=\alpha\left(1-\mathrm{e}^{-i R}\right) .
$$

By a similar reasoning, we can deduce the educational subsidy for the migrants. Thus, the private-maximum first-order condition for potential migrants is readily shown to be

$$
A\left\{-i\left(\alpha^{*}+\beta^{*} f^{*}\right)+\beta^{*} f_{S}^{*}\right\}+i C+G=0,
$$


and for a social maximum it is

$$
A\left\{-i f^{*}+f_{S}^{*}\right\}+i C=0
$$

so that reconciling (24a) and (22a) yields the educational subsidy for the potential migrants as

$$
G=\alpha^{*}\left(1-\mathrm{e}^{-i R}\right)-\left(1-\beta^{*}\right) i C
$$

However, the educational subsidy must evidently be given uniformly to all individuals. Therefore (25) and (25a) should be equated so that we must have

$$
\alpha^{*}=\alpha+\frac{i}{1-\mathrm{e}^{i R}}\left(1-\beta^{*}\right) C=\alpha+\frac{\left(1-\beta^{*}\right)}{A(R)} C,
$$

i.e. if the migration $\operatorname{cost} C$ is negligible, the same intercept must be chosen for the (domestic) income tax, and the income tax on migrants' schedules.

\subsubsection{Decision to migrate}

There remains now the problem of the choice between staying at home and going abroad. One therefore has to choose the tax scheme in such a way as to ensure the socially efficient choice in this regard. In fact, we shall prove that the linear income tax on foreign income combined with educational subsidy and the domestic income tax, satistıes tinis requirement provided that $\beta^{*}$ is set equal to $\beta$.

Now, the condition for the globally efficient choice for deciding to emigrate is

$$
\hat{\Gamma}=\left[\int_{\hat{S}^{*}}^{\hat{S}^{*}+R} f^{*} \mathrm{e}^{-i t} \mathrm{~d} t-C \mathrm{e}^{\cdots i \hat{S}^{*}}\right]-\int_{\hat{S}}^{\hat{S}+R} f \mathrm{e}^{-i t} \mathrm{~d} t>0,
$$

where both $\hat{S}$ and $\hat{S}^{*}$ are chosen to satisfy the marginal condition for securing the efficiency of the length of education. On the other hand, individuals will migrate according to the (private) condition:

$$
\begin{aligned}
\Gamma= & \int_{\hat{S}^{*}}^{\hat{S}^{+}+R}\left(\alpha^{*}+\beta^{*} f^{*}\right) \mathrm{e}^{-i t} \mathrm{~d} t-C \mathrm{e}^{-i \hat{S}^{*}}+G \int_{0}^{\hat{S}^{*}} \mathrm{e}^{-i t} \mathrm{~d} t \\
& -\left[\int_{\hat{S}}^{\hat{S}_{+} R}(\alpha+\beta f) \mathrm{e}^{-i t} \mathrm{~d} t+G \int_{0}^{\hat{S}} \mathrm{e}^{-i t} \mathrm{~d} t\right]>0
\end{aligned}
$$


which, in view of (26), equals:

$$
\begin{aligned}
& \alpha\left[\int_{\hat{S}^{*}}^{\hat{S}^{*}+R} \mathrm{e}^{-i t} \mathrm{~d} t-\int_{\hat{S}}^{\hat{S}+R} \mathrm{e}^{-i t} \mathrm{~d} t\right] \\
& +\left[\int_{\hat{S}}^{\hat{S}^{*}+R} \frac{\left(1-\beta^{*}\right)}{A} C \mathrm{e}^{-i t} \mathrm{~d} t-\left(1-\beta^{*}\right) C \mathrm{e}^{-i \hat{S}^{*}}\right] \\
& +G\left[\int_{0}^{\hat{S}^{*}} \mathrm{e}^{-i t} \mathrm{~d} t-\int_{0}^{\hat{S}} \mathrm{e}^{-i t} \mathrm{~d} t\right] \\
& +\beta^{*}\left[\int_{\hat{S}^{*}}^{\hat{S}^{+}+R} f^{*} \mathrm{e}^{-i t} \mathrm{~d} t-C \mathrm{e}^{-i \hat{S}^{*}}\right]-\beta \int_{\hat{S}}^{\hat{S}+R} f \mathrm{e}^{-i t} \mathrm{~d} t>0 .
\end{aligned}
$$

It is easy to see, however, that the second bracket vanishes. Moreover, if we substitute here $G=\alpha\left(1-\mathrm{e}^{-i R}\right)$, it can be seen that:

$$
\alpha\left[\int_{\hat{S}^{*}}^{\tilde{S}^{*}+R} \mathrm{e}^{-i t} \mathrm{~d} t-\int_{\hat{S}}^{\hat{S}+R} \mathrm{e}^{-i t} \mathrm{~d} t\right]+G\left[\int_{0}^{\hat{S}^{*}} \mathrm{e}^{-i t} \mathrm{~d} t-\int_{0}^{\hat{S}} \mathrm{e}^{-i t} \mathrm{~d} t\right]=0 .
$$

Therefore, the criterion for the private decision on migration reduces to:

$$
\Gamma=\beta^{*}\left[\int_{\hat{S}^{*}}^{\hat{S}^{*}+R} f^{*} \mathrm{e}^{-i t} \mathrm{~d} t-C \mathrm{e}^{-i \hat{S}^{*}}\right]-\beta \int_{\hat{S}}^{\hat{S}+R} f \mathrm{e}^{-i t} \mathrm{~d} t>0
$$

Therefore, if and only if $\beta^{*}$ is set equal to $\beta$, permitting the fulfillment of (26) and (27) simultaneously, will the criterion for the optimal decision for emigration be satisfied.

The equalization of (26) and (27) therefore yields the condition for securing the globally efficient choice on the decision to migrate:

$$
\beta=\beta^{*}
$$

\subsection{Properties of the globally efficient solution}

Therefore, setting the three policy instruments at appropriate values, i.e. those that satisfy (26) and (28), will ensure global efficiency in our open Atkinson economy. 
At the same time, it is immediately obvious that setting $\beta=\beta^{*}$ virtually close to zcro would again ensure, as argued in Hamada (1974), that full equity would be achieved alongside domestic (and, now restricted global) efficiency. Therefore we have a generalization of the closed-economy Hamada (1974) result to an open economy, thanks to the availability of one more instrument (i.e. the income tax on migrants) when the economy is opened. Thus, we can conclude:

Proposition 4. By a combined, appropriate use of the (domestic) income tax, the income tax on migrants and the educational subsidy, (restricted) global efficiency can be achieved while the home country achieves both domestic efficiency and 'almost' full equity. This requires that the marginal rate of laxation for the two income taxes be identical and virtually equal to unity, whereas the intercept for the income tax on migrants' schedule will differ from that for the (domestic) income tax schedule by tirtue of the migration cost.

Now it is obvious that the tax feasibility locus for this globally efficient open economy will lie outside that for the inefficient open economy which cannot use the educational subsidy and the income tax on migrants, so that TLBs ought to improve their welfare. But, we can go beyond the obvious and show something much stronger: namely, that our generalized solution of efficiency plus virtually full equity constitutes also the first-best, i.e. the welfare-maximizing, solution for TLBs. For global efficiency implics that world output, produced by both TLBs and migrants, is maximized provided that there is no distortion abroad. At the same time, $\beta^{*} \rightarrow 0$ implies that maximal revenue is being collected by the home country $\left(\alpha^{*}\right.$ cannot be reduced below $\alpha$ without both disrupting the efficiency condition and eliminating migration altogether and therefore resulting in a closed economy, given $\beta=\beta^{*} \rightarrow 0$ ). Therefore, TLB welfare ought to be at a maximum in this solution. Thus we can conclude:

Proposition 5. The solution in proposition 4 is, at the same time, the welfaremaximizing first-best solution for TLBS.

Note finally that $\beta^{*}$ is the marginal slope of the disposable income of the migrants net of both foreign-country and the home-country income taxes. How then are $\beta$ and $\beta^{*}$ to be equated by the home country given the fact that the foreign-country tax schedule is to be considered as exogenously determined? This equality can be achieved simply in the following way. First, let the home country extend its (domestic) income tax schedule to migrants. Second, as per double-taxation-avoidance arrangements, let the tax payments to the foreign country be made deductible as tax credits from tax liability to the home country. Third, to allow for the migration cost $(C)$ complication already noted, let amount $\left(1-\beta^{*}\right) i C$ be credited also against the tax liability 
of the migrants to the home country. The satisfaction of the first two conditions will then ensure that $\beta=\beta^{*}$ and, of the third, will ensure that the required relationship between $\alpha$ and $\alpha^{*}$ [in eq. (26)] will also be satisfied, provided the marginal income tax rate for the foreign country is less than that of the home country. ${ }^{26,27}$

\section{Concluding observations}

The main objective of the present paper has been to initiate a formal public-finance-theoretic analysis of an important policy issue that has come to attract attention from policymakers: namely, the exercise of home-country income tax jurisdiction over nationals working abroad.

Our main results have been developed by assuming that the home country maximized the welfare of the TLBs ('those left behind'). This social objective may appear reasonable to policymakers even though nationals who work abroad are part of the national population, especially if the TLBs are at the lower end of unadjusted income distribution and the migrants at the upper end. Our welfare criterion can be regarded as an extension of the Rawls criterion, not applied to the individual with minimum income but to a predetermined band of individuals who are in lower income brackets. On the other hand, one may well want to ask what happens to the migrants' welfare in our exercises in this paper since policies that improve the welfare of the TLBs may well be worsening that of the migrants, resulting in a trade-off that may need to be addressed in policymaking. ${ }^{28}$ To adapt our analysis to this newly defined objective function, which extends over the augmented and full set of nationals, we do not need to amend the derivation of the tax feasibility loci in the analysis but rather to amend the (indirect) social indifference curves defined on the tax parameters. We hope to return to this task in another paper.

\section{Appendix}

This appendix is designed to prove some properties of the $h(n)$ function, the tax feasibility locus, and the social welfare function. These properties are

\footnotetext{
${ }^{26}$ As Hamada (1978) has noted, this proviso is generally satisfied for migration from the developing to the developed countries. The extension of domestic tax schedules to migrants, with double-taxation relief, was proposed there as a device to restore global efficiency in a twocountry world

${ }^{27}$ Of course, one cannot actually recommend this first-best solution without reservations. In the real world, the threshold of perception or incentives may be quite high. Moreover, the administrative cost of redistribution may not be negligible. Our analysis in this section only shows that there is a structure implied in the model of income taxation deployed such that the conflict between equity and efficiency can be undone by a combination of proper instruments.

${ }^{28}$ The delicate issue of comparing the welfare of different groups of people, in an environment where equity and efficiency considerations interact, is beautifully analyzed in the companion paper by Baumol (1982) in this Symposium.
} 
utilized in the text, as noted at appropriate places. We define, as in the text,

$$
h\left(n^{*}\right) \equiv\left(1-n^{*-\mu}\right) /\left(1-n^{*-\mu+1}\right) .
$$

Remark 1. If $n^{*}>1$, and $\mu>1$, then $h\left(n^{*}\right)>1$.

Proof:

$$
h\left(n^{*}\right)-1=\frac{n^{*-\mu+1}-n^{*-\mu}}{1-n^{*-\mu+1}}>0, \text { for } n^{*}>1
$$

Remark 2. If $n^{*}>\mu /(\mu-1)$, then $h^{\prime}\left(n^{*}\right)<0$.

Proof.

$$
h^{\prime}\left(n^{*}\right)=\frac{-(\mu-1) n^{*-\mu-1}\left\{n^{*}-\frac{\mu}{\mu-1}\right\}-n^{*-2 \mu}}{\left(1-n^{*-\mu+1}\right)^{2}}<0 .
$$

Remark 3. The slope of tangent line to the opportunity locus expressed by eq. (14) in the text is steeper than $1 / \bar{n}$ as long as the opportunity locus is downward-sloping.

Proof: Totally differentiating (14), taking account of the fact that $n$ * depends on $\beta$ and $n_{0}$, one obtains:

$$
\mathrm{d} \beta=-\frac{\mathrm{d} n_{0}}{\bar{n}} h\left(n^{*}\right)-\frac{n_{0}}{\bar{n}} h^{\prime}\left(n^{*}\right)\left(\frac{\partial n^{*}}{\partial \beta} \mathrm{d} \beta+\frac{\partial n^{*}}{\partial n_{0}} \mathrm{~d} n_{0}\right) .
$$

Therefore

$$
\frac{\mathrm{d} \beta}{\mathrm{d} n_{0}}=-\frac{1}{\bar{n}}\left\{h\left(n^{*}\right)+n_{0} h^{\prime}\left(n^{*}\right) \frac{\partial n^{*}}{\partial n_{0}}\right\} /\left\{1+\frac{n_{0}}{\bar{n}} h^{\prime}\left(n^{*}\right) \frac{\partial n^{*}}{\partial \beta}\right\} .
$$

When the opportunity locus is downward-sloping, the denominator in the brace is positive. (If the denominator changes its sign from positive to negative, then the opportunity locus becomes tangent to a vertical line at some value of $\beta$ and tilts into an upward-sloping locus. However, this upward-sloping locus does not interest us because the point on this portion of locus can sever be efficient.) 
On the other hand, from (11), (13) and the definition of $n_{0}$, one obtains:

$$
I_{\mathrm{d}}=\frac{A n}{i e} \beta \exp \left(\frac{n_{0}}{n}\right) \text {. }
$$

It is easy to notice that a marginal change in $n_{0}$ shifts the $I_{\mathrm{d}}$ schedule just $\beta / n^{*}$ times as the change of $\beta$ shifts it. Therefore, by applying the same reasoning as used to derive (5) (cf. fig. 1), one obtains:

$$
\frac{\partial n^{*}}{\partial n_{0}}=\frac{\beta}{n^{*}} \frac{\partial n^{*}}{\partial \beta} .
$$

Therefore,

$$
\begin{aligned}
& \left\{h\left(n^{*}\right)+n_{0} h^{\prime}\left(n^{*}\right) \frac{\partial n}{\partial n_{0}}\right\} /\left\{1+\frac{n_{0}}{\bar{n}} h^{\prime}\left(n^{*}\right) \frac{\partial n^{*}}{\partial \beta}\right\} \\
& =h\left(n^{*}\right)\left\{1+\frac{\beta}{n^{*} h\left(n^{*}\right)}\left(n_{0} h^{\prime}\left(n^{*}\right) \frac{\partial n^{*}}{\partial \beta}\right)\right\} /\left\{1+\frac{1}{\bar{n}}\left(n_{0} h^{\prime}\left(n^{*}\right) \frac{\partial n^{*}}{\partial \beta}\right)\right\} .
\end{aligned}
$$

Because $h\left(n^{*}\right)>1, \beta<1$ and $n^{*}>\bar{n}$, we get:

$$
\frac{\beta}{n^{*} h\left(n^{*}\right)}<\frac{1}{\bar{n}}
$$

Since $n_{0} h^{\prime}\left(n^{*}\right)\left(\partial n^{*} / \partial \beta\right)$ is negative, and since the denominator is assumed to be positive, one can conclude from (A4) that the r.h.s. of eq. (A3) is larger than $h\left(n^{*}\right)$, because the brace in the numerator is larger than the brace in the denominator, which itsclf is positive. Therefore, we can conclude from (A1) and (A3) that:

$$
\frac{\mathrm{d} \beta}{\mathrm{d} n_{0}}<-\frac{1}{\bar{n}}
$$

which is in fact (15).

Remark 4. The absolute slope of the indifference curve is an increasing function of $n_{0}$ along a horizontal line if $\rho<1$, and a decreasing function of $n_{0}$ if $\rho>1$. 
Proof. The Schwarz Inequality says [e.g. Royden (1968, p. 210)]: Let $g_{1}$ and $g_{2}$ be integrable functions with respect to $\mathrm{d} F$. Then

$$
\left|\int g_{1} \mathrm{~d} F\right| \cdot\left|\int g_{2} \mathrm{~d} F\right| \geqq\left[\int g_{1} g_{2} \mathrm{~d} F\right]^{2} .
$$

Let us write, for economy of space:

$$
\begin{aligned}
& \int_{1}^{N} n^{-\rho} \exp \left[(1-\rho) n_{0} / n\right] p(n) \mathrm{d} n \equiv \int n^{-\rho}, \\
& \int_{1}^{N} n^{1-\rho} \exp \left[(1-\rho) n_{0} / n\right] p(n) \mathrm{d} n \equiv \int n^{1-\rho},
\end{aligned}
$$

and so forth.

Then

$$
\begin{aligned}
\frac{\hat{\partial}}{\hat{\partial n_{0}}}\left[-\frac{\mathrm{d} \beta}{\mathrm{d} n_{0}}\right] & =\beta \frac{\partial}{\partial n_{0}}\left[\int n^{-\rho} / \int n^{1-\rho}\right] \\
& =\beta(1-\rho) \frac{\left[\int n^{-1-\rho}\right]\left[\int n^{1-\rho}\right]-\left[\int n^{-\rho}\right]^{2}}{\left[\int n^{1-\rho}\right]^{2}} \\
& \begin{cases}>0, & \text { if } \rho<1, \\
<0, & \text { if } \rho>1 .\end{cases}
\end{aligned}
$$

For, by the Schwarz inequality applied to $\mathrm{d} F=\exp \left[(1-\rho) n_{0} / n\right] p(n) \mathrm{d} n$

$$
\left[\int n^{-1-\rho}\right]\left[\int n^{1-\rho}\right] \geqq\left[\int n^{-\rho}\right]^{2}
$$

and the equality does not hold because the integrands are not proportional to each other.

\section{References}

Atkinson, A.B., 1973, How progressive should income tax be?, in: M. Parkin, ed., Fssays in modern economics (Longman, London).

Baumol, W.B., 1982, The income distribution frontier and taxation of migrants, Journal of Public Economics 18, this issue.

Bhagwati, J., 1972, The United States in the Nixon era: The end of innocence, Daedalus.

Bhagwati, J. 1976, ed., The brain drain and taxation: Theory and empirical analysis (NorthHolland, Amsterdam).

Bhagwati, J., 1979, International migration of the highly skilled: Economics, ethics and taxes. Third World Quarterly 1, 17-30. 
Bhagwati, J. and W. Dellalfar, 1973, The brain drain and income taxation, World Development 1, 94-101.

Bhagwati, J. and K. Hamada, 1974, The brain drain, international integration of markets for professionals and unemployment: A theoretical analysis, Journal of Development Economics 1; reprinted in revised version in Bhagwati (1976).

Bhagwati, J. and M. Partington, eds., 1976, Taxing the brain drain: A proposal (North-Holland, Amsterdam).

Bhagwati, J. and C. Rodriguez, 1975, Welfare-theoretical analyses of the brain drain. Journal of Development Economics 2; reprinted in Bhagwati (1976).

Cooper, P.N., 1973, Economic mobility and national economic policy (Almquist and Wicksell International, Stockholm).

Hamada, K., 1966, Strategic aspects of taxation on foreign investment income, Quarterly Journal of Economics 80, 351375.

Hamada, K., 1972, Lifetime equity and dynamic efficiency on the balanced growth path, Journal of Public Economics 1, 379-396.

Hamada, K., 1974. Income taxation and educational subsidy, Journal of Public Economics 3 , $145-158$.

Hamada, K., 1975, Efficiency, equity, income taxation and the brain drain: A second best argument, Journal of Development Economics 2, 281-287.

Hamada, K., 1978. Taxing the brain drain: A global point of view, in: J. Bhagwati, ed., The new international economic order: The north-south debate (MIT Press) ch. 5.

Harris, I. and M. Todaro, 1970, Migration, unemployment and development: A 1wo-sector analysis, American Economics Review 60, 126-142.

McCulloch, R. and J. Yellen, 1975, Consequences of a tax on the brain drain for urmemployment and income inequality in the LDCs, Journal of Developments Economics 2; reprinted in Bhagwati (1976).

Mirrlees, J.A., 1971, An exploration in the theory of optimum income taxation. Review of Economic Studies 38, 175-208.

Oldman, Oliver and Richard Pomp, 1975, The brain drain: A tax analysis of the Bhagwati proposal, World Development 3; reprinted in Bhagwati (1976).

Oldman. Oliver and Richard Pomp, 1977. Consideration of policy issues at the international level, legal and administrative aspects of compensation, taxation and related policy measures: Suggestions for an optimal policy mix, Paper for the Intergovernmental Group of Experts Meeting at UNCTAD, Geneva, UN Doc. TD/B/C.6/AC.4/7, Geneva.

Oldman, Oliver and Richard Pomp, 1979, Tax measures in response to the brain drain, Harvard International Law Journal 20, Winter.

Rawls, John, 1971, A theory of justice (Harvard University Press).

Rodriguez, D., 1975, Brain drain and economic growth: A dynamic model, Journal of Development Economics 2.

Royden, H.L.. 1968. Real analysis, 2nd edn. (Macmillan. New York).

Wilson, John D., 1978, The effect of potential emigration on the optimal linear income lax. Journal of Public Economics 14, 339-353. 